\title{
CONTRACT DE-AC01-87EH79003
}

\section{TECHNICAL PROGRESS REPORT}

FOR

\begin{abstract}
Technical Support Services to Assist the Office of Environmental Audit in Conducting the DOE Environmental Survey and to Provide

Technical Assistance on Environmental Compliance Issues
\end{abstract}

Period: February 16, 1991 - August 16, 1991

Submitted to

U.S. Department of Energy 1000 Independence Avenue

Washington, D.C. 20585

Submitted by

HALLIBURTON NUS Environmental Corporation

910 Clopper Road

Gaithersburg, MD 20877

() HALLLBURTON NUS

DISTRIBUTION OF THIS DOCUMENT IS UNLIMITEDT

MASTER 


\section{DISCLAIMER}

This report was prepared as an account of work sponsored by an agency of the United States Government. Neither the United States Government nor any agency thereof, nor any of their employees, make any warranty, express or implied, or assumes any legal liability or responsibility for the accuracy, completeness, or usefulness of any information, apparatus, product, or process disclosed, or represents that its use would not infringe privately owned rights. Reference herein to any specific commercial product, process, or service by trade name, trademark, manufacturer, or otherwise does not necessarily constitute or imply its endorsement, recommendation, or favoring by the United States Government or any agency thereof. The views and opinions of authors expressed herein do not necessarily state or reflect those of the United States Government or any agency thereof. 


\section{DISCLAIMER}

Portions of this document may be illegible in electronic image products. Images are produced from the best available original document. 
CONTRACT DE-AC01-87EH79003

\title{
TECHNICAL PROGRESS REPORT
}

FOR

\begin{abstract}
Technical Support Services to Assist the Office of Environmental Audit in Conducting the DOE Environmental Survey and to Provide Technical Assistance on Environmental Compliance Issues
\end{abstract}

Period: February 16, 1991 - August 16, 1991

Submitted to

U.S. Department of Energy 1000 Independence Avenue

Washington, D.C. 20585

Submitted by

HALLIBURTON NUS Environmental Corporation

910 Clopper Road

Gaithersburg, MD 20877

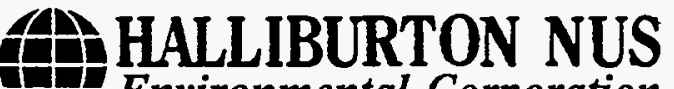

\# Environmental Corporation 
TABLE OF CONTENTS

Section

Page

1.0 INTRODUCTION

1.1 Background

1.2 Overview of Technical Effort

1.2.1 Environmental Surveys

1.2.2 Prioritization

1.2.3 Environmental Compliance

1.2.4 Reactor Safety Study

1.2.5 Brookhaven Reactor Study

1.2.6 Program Management

1.2.7 Environmental Survey Manual

1.2.8 General Survey Support Training

1.2.9 Prioritization

1.2.10 Tiger Team Assessments

1.2.11 Environmental Audits

1.2.12 Continuity of Services

$1-1$

$1-1$

$1-2$

$1-3$

$1-3$

$1-4$

$1-4$

$1-4$

$1-4$

$1-5$

$1-5$

$1-5$

$1-6$

$1-6$

$1-7$

2.0 TECHNICAL SUMMARY 2-1

2.1 Environmental Surveys

2.1.1 Feed Materials Production Center (FMPC) Survey

$2-1$

2.1.2 Mound Plant Survey

2.1.3 Rocky Flats Plant (RFP) Survey

2-1

$2-1$

2.1.4 Portsmouth Gaseous Diffusion Plant Survey

2-1

2.1.5 Hanford Survey

2.1.6 Pantex Plant Survey

2.1.7 Oak Ridge $Y-12$ Plant Survey

2.1.8 Sandia National Laboratories, Livermore (SNLL) Survey

2.1.9 Lawrence Livermore National Laboratory (LLNL) Survey

$2-1$

2-1

$2-2$

$2-2$

$2-2$

$2-2$

2.1.10 Savannah River Site (SRS) Survey 2-2

2.1.11 Kansas City Plant (KCP) Survey $2-2$

2.1.12 Los Alamos National Laboratory (LANL) Survey $\quad 2-2$

2.1.13 Pinellas Plant Survey

2.1.14 Brookhaven National Laboratory (BNL) Survey 2-3

2.1.15 Nevada Test Site (NTS) Survey

2.1.16 Fermilab Survey

2.1.17 Argonne National Laboratory (ANL) Survey

2.1.18 Sandia National Laboratories - Albuquerque (SNLA) Survey

2.1.19 Oak Ridge National Laboratory $(X-10)$ Survey

$2-3$

$2-3$

$2-3$

$2-3$

2.1.20 Paducah Gaseous Diffusion Plant Survey

2.1.21 Morgantown Energy Technology Center (METC) Survey

$2-3$

$2-4$

2.1.22 Pittsburgh Energy Technology Center (PETC) Survey

2.1.23 Idaho National Engineering Laboratory/Component Development and Integration Facility (INEL/CDIF) Survey 


\section{TABLE OF CONTENTS \\ (Continued)}

2.1.24 Lawrence Berkeley Laboratory (LBL) Survey

2.1.25 Stanford Linear Accelerator Center (SLAC) Survey

Solar Energy Research Institute (SERI) Survey

2.1 .27

Strategic Petroleum Reserves (SPR) Survey

$2-4$

2.1 .28

Oak Ridge Gaseous Diffusion Plant (ORGDP)

Survey

2.1.29 Laboratory for Energy-Related Health

Research (LEHR) Survey

2-4

2-4

$2-5$

2.1.30 Bonneville Power Administration/Western

Area Power Administration (BPANAPA) Survey

2.1.31 National Institute for Petroleum and Energy

Research (NIPER) Survey

2.1.32 Santa Susana Field Laboratories (SSFL) Survey

2.1.33

Waste Isolation Pilot Plant (WIPP) Survey

2.1.34

Ames Laboratory Survey

2.1.35 Naval Petroleum and Oil Shale Reserves

(NPOSR) Survey

2.1.36 Princeton Plasma Physics Laboratory (PPPL)

Survey

2.1.37 Naval Petroleum Reserves - California (NPRC) Survey

2.2 Prioritization

2.3 Environmental Compliance

2.4 Reactor Safety Study

2.5 Brookhaven Reactor Study

2.6 Sampling and Analysis

2.7 Survey Follow-Up

2.8 Trend Analysis

2.9 Protocols for Preparation and Production of Tiger Team

Assessment Reports

2.10 Tiger Team Assessments

2.10.1 Y-12 Plant Tiger Team Assessment

2.10.2 Pinellas Plant Tiger Team Assessment

2.10.3 Mound Plant Tiger Team Assessment

2.10.4 Pantex Plant Tiger Team Assessment

2.10.5 Nevada Test Site Tiger Team Assessment

2.10.6 Kansas City Plant Tiger Team Assessment

2.10.7 Portsmouth Tiger Team Assessment

2.10.8 Lawrence Livermore National Laboratory (LLNL) Tiger Team Assessment

2.10.9 Brookhaven National Laboratory Tiger Team Assessment

2.10.10 Sandia National Laboratories (SNL), Livermore Tiger Team Assessment

2.10.11 Paducah Gaseous Diffusion Plant Tiger Team Assessment

2.10.12 Hanford Tiger Team Assessment

2.10.13 Argonne National Laboratory Tiger Team Assessment 


\section{TABLE OF CONTENTS \\ (Continued)}

Section

Page

2.10.14 Oak Ridge National Laboratory Tiger Team Assessment

2.10.15 Lawrence Berkeley Laboratory Tiger Team Assessment

2.10.16 Princeton Plasma Physics Laboratory Tiger Team Assessment

2.11 Environmental Audits

2.11.1 Bonneville Power Administration Environmental

Audit

2.11.2 Maywood Interim Storage Site Environmental Audit

2.11.3 Western Area Power Administration Environmental Audit

2.11.4 North Las Vegas Facility Environmental Audit

2.12 Continuity of Services

2-10

2.12.1 Sandia National Laboratories-Albuquerque

2-10

2.12.2 Idaho National Engineering Laboratory

2-10

2.12.3 Morgantown Energy Technology Center

2-10

2.12.4 Solar Energy Research Institute

2-11

2.12.5 West Valley Demonstration Project

2-11

2-11

2.13 Program Management

2-11 
HALLIBURTON NUS received authorization from DOE on August 14, 1987 to provide technical support services to assist the Office of Environmental Audit (OEV) in conducting the DOE Environmental Survey and to provide technical assistance on environmental compliance issues. HALLIBURTON NUS has completed the Preliminary Reports and continues to support DOE on the Prioritization and Tiger Team Assessment efforts.

\section{$1.1 \quad$ Background}

HALLIBURTON NUS is submitting this Technical Progress Report in compliance with the Reporting Requirements Checklist contained in Contract No. DE-AC01$87 E H 79003$.

As of August 16, 1991, DOE issued 30 task assignments and amendments under the previously mentioned contract, shown as follows:

Task No.

Activity

$1 / A-1$

2/A-E

3/A-D

4/A-B

5/A-E

6/A-B

$7 / A$

8/A-B

9/A-B

10/A-E

11/A-B

12/A-D

13/A-B

$14 / A-B$

$15 / A-B$

$16 / A-B$

$17 / A$

19/A-C
Project Management

New Surveys

DP Prioritization

HFBR Emergency Cooling Core

Continued Surveys

Environmental Compliance

Nuclear Reactor Review

Environmental Survey Manual

General Survey Support

Non-DP Prioritization

Sampling \& Analysis

Tiger Teams (1st Round)

Tiger Teams (2nd Round)

Tiger Teams (3rd Round)

Hanford Tiger Team Assessment

Paducah Tiger Team Assessment

Administrative Assistance

Protocols for Preparation and Production of

Tiger Team Assessment Reports 
20/A

21/A

22/A

23/A

24/A-B

25/A

26/A

27/A

28

29

30

31
Bonneville Power Administration

Environmental Audit

Argonne National Laboratory Tiger Team

Assessment

Oak Ridge National Laboratory Tiger Team

Assessment

Bonneville Power Administration

Environmental Audit

Argonne National Laboratory Tiger Team

Assessment

Oak Ridge National Laboratory Tiger Team

Assessment

Maywood Interim Storage Site Environmental

Audit

Western Area Power Administration

Environmental Audit

Lawrence Berkeley Laboratory Tiger Team

Assessment

North Las Vegas Facility Environmental Audit

Princeton Plasma Physics Laboratory Tiger Team

Assessment

Continuity of Services

\subsection{Overview of Technical Effort}

The overall contract is to accomplish a one-time, no-fault baseline Survey of all DOE operating facilities, and to provide technical assistance and support for the resolution of environmental compliance issues. The following sections will provide an overview of individual tasks assigned by DOE under this contract.

This project requires a broad range of environmental protection expertise, necessitating senior-level personnel as the primary project staff. Many of the tasks assigned by DOE require quick startup and performance, and several tasks may be active at any one time. 


\subsubsection{Environmental Surveys}

The objective of the DOE Environmental Survey Program is to identify and prioritize areas of existing environmental risk at 36 DOE facilities. HALLIBURTON NUS' role is to technically assist the Office of Environmental Audit in the implementation of the Surveys. Both Task Assignments 2/A-E and 5/A-E include a ten-point scope of work:

1. File Review

2. Site Information Request Letter

3. Pre-Survey Site Visit

4. Federal and State Environmental Coordination

5. Strategy Meeting/Site Plan

6. On-Site Survey

7. Sampling and Analysis Requests

8. Preliminary Report

9. Sampling and Analysis Interpretation

10. Interim Report - Identify Problems Requiring Immediate Action

Coordination of Sampling and Analysis work with the Survey reports was anticipated.

\subsubsection{Prioritization}

The Phase I and II Prioritization task (Task Assignment 3) was assigned to evaluate and rank problems and areas of risk found during the Environmental Surveys at DOE sites. The first phase of the effort was directed at prioritizing 16 Defense Program sites and one Non-Defense Program site. The second phase of the effort was directed at prioritizing 19 Non-Defense Program sites. The third phase of the effort has been directed at refining the preliminary prioritization of all sites included in Phases I and II, and is described in Section 1.2.9.

No activities were conducted during the report period for Phases I and II. 


\subsubsection{Environmental Compliance}

DOE issued Task Assignment 6 to HALLIBURTON NUS to provide technical assistance to the Office of Environmental Guidance and Compliance. This task involves analyzing environmental compliance issues which had an effect or had the potential for affecting the Department's operations. Task Assignment 6/A was issued on July 15, 1988 to discontinue Task 6.

\subsubsection{Reactor Safety Study}

HALLIBURTON NUS' Task Assignment 7 from DOE was to provide general technical assistance and support relating to compliance requirements in the development and coordination of action plans required as a result of the study conducted by the National Academy of Science and Engineering (NAS) and which are contained in the report Safety Issues at the Defense Production Reactors.

\subsubsection{Brookhaven Reactor Study}

Task Assignment 4/A was issued for HALLIBURTON NUS to provide general technical support in the safety evaluation of the HFBR reactor at Brookhaven National Laboratory. The following areas were included in the scope of work:

1. Propagation of Core Meeting

2. Effect of Noncondensables on CHF

3. HFBR Leak-Before-Break-Assessment

4. Use of the Effective Break Area

\subsubsection{Program Management}

This task was assigned by DOE for HALLIBURTON NUS Project Management to ensure that all Environmental Survey teams operate in a consistent and uniform manner. Program Management also ensures that all reports and deliverables will be prepared under a high degree of quality assurance/quality control which is consistent with the requirements of the program. 
HALLIBURTON NUS was assigned Task 8 to provide technical support in reviewing and correcting the DOE Environmental Survey Manual, to ensure that it is up-to-date and consistent with changes made by the OEV in Survey policy.

\subsubsection{General Survey Support Training}

Task Assignment 9 was issued by DOE so HALLIBURTON NUS could technically assist the Office of Environmental Audit in training for: the use of MEPAS (Multimedia Environmental Pollutant Assessment System Shell); Sampling and Analysis Interpretation; and Technial Accuracy Review Comment Response.

\subsubsection{Prioritization}

Task Assignment 10 was issued for HALLIBURTON NUS to continue providing technical assistance in implementing the prioritization system for those problems and areas of risk which have been identified in the Environmental Surveys by utilizing the MEPAS program for Non-DP sites and refining the preliminary prioritization of all sites included in Phases I and II, as described in Section 1.2.2.

The following activities were conducted prior to this reporting period for Phase III:

1. Prepared worksheets for use in the MEPAS model.

2. Extracted and input appropriate data into the MEPAS model.

3. Attended technical staff meetings, as appropriate.

4. Prepared Prioritization Letter Reports.

5. Executed the MEPAS model to obtain preliminary HPI rankings.

6. Developed Draft Appendices for each of the $\mathbf{3 6}$ sites and participated in Data Accuracy Review (DAR) meetings.

7. Incorporated site comments from the DAR meeting, and input new or additional data for certain sites.

8. Developed the Risk Information System and modified the Draft Appendices to incorporate the RIS criteria. 


\subsubsection{Tiger Team Assessments}

In August 1989, DOE requested support from HALLIBURTON NUS for the environmental portion of multiple Tiger Team Assessments. Activities included:

- Compile and maintain a repository and assist in reviewing environmental reports, data bases and other pertinent information to develop an understanding of the conditions and operations of DOE facilities to be assessed and prepare a list of records and files that the assessment team should review while on-site.

- Prepare a detailed site-specific assessment plan and agenda.

- Provide technical assistance in conducting the on-site assessment.

- Provide technical assistance in the development of Sampling and Analysis plans.

- Provide written reports as required for use in developing the predecisional draft and final assessment reports.

- Assist DOE in developing Tiger Team environmental performance objectives and criteria.

\subsubsection{Environmental Audits}

In August 1990, DOE requested support from HALLIBURTON NUS to perform Environmental Audits at DOE facilities.

Activities included in the Audits are:

- Compile and maintain a repository, and assist in reviewing environmental reports, data bases, and other information to develop an understanding of the conditions and operations of the particular DOE facility. 
- Provide written, detailed, site-specific Audit Plans which will include but are not limited to the following:

- identification and summaries of key site issues;

- agenda for on-site activities (including interviews, record reviews, observation visits, document reviews and operations); and

- list of records, files and other documents reviewed by the Audit team while on-site.

\subsubsection{Continuity of Services}

In March 1991, DOE requested that HALLIBURTON NUS provide continuity of services support to the Office of Environmental Audit and Office of Special Projects. This task has included:

- Assisting DOE and the new contractor, A. D. Little ( $A D L$ ), in planning assessment and audit activities and in providing historical perspective on the DOE assessment approach;

- Assisting $A D L$ in understanding their role and support to be provided to DOE; and

- Providing technical assistance, advice, and support to the the DOE Environmental Subteam Leaders in technical coordination areas throughout the assessment process.

These services have been provided for the Sandia National LaboratoriesAlbuquerque, Morgantown Energy Technology Center, ldaho National Engineering Laboratory, and Solar Energy Research Institute Tiger Teams and the West Valley Demonstration Project Audit. 
This section of the report describes the technical progress of each of the task assignments, with particular focus on the specific sites visited on the Environmental Surveys.

\subsection{Environmental Surveys}

HALLIBURTON NUS assisted the Office of Environmental Audit by sharing their Survey/audit experiences with other contractors as directed by DOE, and reviewing Survey/audit protocols.

\subsubsection{Feed Materials Production Center (FMPC) Survey}

From February through April, no work was performed on the FMPC Survey. Some file closeout activities occurred during May. No work was performed on the FMPC Survey from June through August.

\subsubsection{Mound Plant Survey}

No technical activities were performed during the reporting period.

\subsubsection{Rocky Flats Plant (RFP) Survey}

No technical activities were performed during the reporting period.

\subsubsection{Portsmouth Gaseous Diffusion Plant Survey}

Minor file review and closeout activities took place during this period.

\subsubsection{Hanford Survey}

The use of Survey S\&A data was incorporated into the Draft Appendix for Hanford from February through May. No work was performed on the Hanford Survey during June. The use of S\&A data was incorporated into the Draft Appendix for the Hanford Survey during August and September. 


\subsubsection{Pantex Plant Survey}

No technical activities were performed during the reporting period.

\subsubsection{Oak Ridge Y-12 Plant Survey}

No technical activities were performed during the reporting period.

\subsubsection{Sandia National Laboratories, Livermore (SNLL) Survey}

Minor file review and closeout activities took place during this period.

\subsubsection{Lawrence Livermore National Laboratory (LLNL) Survey}

Minor file review and closeout activities took place during this period.

\subsubsection{Savannah River Site (SRS) Survey}

In February and March, file closeout activities were performed on the SRS Survey. No work was performed on the SRS Survey during April. Additional file closeout activities occurred during May. No work was performed on the SRS Survey from June through August.

\subsubsection{Kansas City Plant (KCP) Survey}

No technical activities were performed during the reporting period.

\subsubsection{Los Alamos National Laboratory (LANL) Survey}

No technical activities were performed during the reporting period. 


\subsubsection{Pinellas Plant Survey}

In February, no work was performed on the Pinellas Survey. File closeout activities occurred during March. No work was performed on the Pinellas Survey from April through August.

\subsubsection{Brookhaven National Laboratory (BNL) Survey}

Minor file review and closeout activities took place during this period.

\subsubsection{Nevada Test Site (NTS) Survey}

No technical activities were performed during the reporting period.

\subsubsection{Fermilab Survey}

Minor file review and closeout activities took place during this period.

\subsubsection{Argonne National Laboratory (ANL) Survey}

There was no technical activity on this Survey during this reporting period.

\subsubsection{Sandia National Laboratories - Albuquerque (SNLA) Survey}

In February, work on the SNLA Survey consisted of file closeout activities during February and March. No work was performed on the SNLA Survey during April. Additional file closeout activities were performed during May. No work was performed on the SNLA Survey during June, July, and August.

\subsubsection{Oak Ridge National Laboratory (X-10) Survey}

No technical activities were performed during the reporting period.

\subsubsection{Paducah Gaseous Diffusion Plant Survey}

Minor file review and closeout activities took place during this period. 


\subsubsection{Morgantown Energy Technology Center (METC) Survey}

No technical activities were performed during the reporting period.

\subsubsection{Pittsburgh Energy Technology Center (PETC) Survey}

No technical activities were performed during the reporting period.

2.1.23 Idaho National Engineering Laboratory/Component Development and Integration Facility (INEL/CDIF) Survey

Except for minor file closeout functions, there was no activity on this Survey during this period.

\subsubsection{Lawrence Berkeley Laboratory (LBL) Survey}

In February, no work was performed on the LBL Survey. Some file closeout activities occurred during March. No work was performed on the LBL Survey during April. Additional file closeout activities occurred during May. No work was performed on the LBL Survey from June through August.

\subsubsection{Stanford Linear Accelerator Center (SLAC) Survey}

In February, no work was performed on the SLAC Survey. Some file closeout activities occurred during March. No work was performed on the SLAC Survey during April. Additional file closeout activities occurred during May. No work was performed on the SLAC Survey from June through August.

\subsubsection{Solar Energy Research Institute (SERI) Survey}

There was no activity on this Survey during this reporting period.

\subsubsection{Strategic Petroleum Reserves (SPR) Survey}

There was no technical activity on this Survey during this reporting period. 


\subsubsection{Oak Ridge Gaseous Diffusion Plant (ORGDP) Survey}

Minor file review and closeout activities took place during this period.

\subsubsection{Laboratory for Energy-Related Health Research (LEHR) Survey}

From February through April, no work was performed on the LEHR Survey. Some file closeout activities occurred during May. No work was performed on the LEHR Survey from June through August.

2.1.30 Bonneville Power Administration/Western Area Power Administration (BPA/WAPA) Survey

DOE decided to delete these sites from the Environmental Survey after reviewing further information.

\subsubsection{National Institute for Petroleum and Energy Research (NIPER) Survey}

There was no technical activity on this Survey during this reporting period.

\subsubsection{Santa Susana Field Laboratories (SSFL) Survey}

Minor file review and closeout activities took place during this period.

\subsubsection{Waste Isolation Pilot Plant (WIPP) Survey}

DOE decided to delete this site from the Environmental Survey after reviewing further information.

\subsubsection{Ames Laboratory Survey}

There was no activity on this Survey during this reporting period. 


\subsubsection{Naval Petroleum and Oil Shale Reserves (NPOSR) Survey}

No technical activities were performed during the reporting period.

\subsubsection{Princeton Plasma Physics Laboratory (PPPL) Survey}

There was no activity on this Survey during this reporting period.

\subsubsection{Naval Petroleum Reserves - California (NPRC) Survey}

No technical activities were performed during the reporting period.

\subsection{Prioritization}

Under Phases I and II, no activities were conducted during this reporting period.

Nine ranking units (RUs) at two sites (ORNL and ORGDP) were modified and rerun as a result of an inconsistency between MEPAS and RIS. The corresponding Draft Appendices were revised to incorporate the modifications. A RU for LLNL was also rerun to incorporate model modifications made by PNL. Throughout the period, production work continued on all Draft Appendices. On August 9, 1991, a meeting was held with DOE to plan for the Environmental Survey Final Reports. Development and production work was then initiated to adapt the Draft Appendices into Final Reports.

\subsection{Environmental Compliance}

This task was closed on July 15, 1989.

\section{$2.4 \quad$ Reactor Safety Study}

There was no technical activity for this task during this reporting period.

\subsection{Brookhaven Reactor Study}

There was no technical activity for this task during this reporting period. 


\subsection{Sampling and Analysis}

There was no technical activity for this task during this reporting period.

\section{$2.7 \quad$ Survey Follow-Up}

There was no activity for this task during this reporting period.

\section{$2.8 \quad$ Trend Analysis}

There has been no activity during this reporting period.

2.9 Protocols for Preparation and Production of Tiger Team Assessment Reports

There has been no activity on this task during this reporting period.

\section{$2.10 \quad$ Tiger Team Assessments}

\subsubsection{Y-12 Plant Tiger Team Assessment}

No technical activities were performed during the reporting period.

\subsubsection{Pinellas Plant Tigẹr Team Assessment}

No technical activities were performed during the reporting period.

\subsubsection{Mound Plant Tiger Team Assessment}

No work was performed on the Mound Tiger Team Assessment during this period.

\subsubsection{Pantex Plant Tiger Team Assessment}

There was no activity on this task during this reporting period. 


\subsubsection{Nevada Test Site Tiger Team Assessment}

No technical work related to this site was conducted during this reporting period.

\subsubsection{Kansas City Plant Tiger Team Assessment}

There was no activity during this reporting period.

\subsubsection{Portsmouth Tiger Team Assessment}

No technical work was performed during this reporting period.

\subsubsection{Lawrence Livermore National Laboratory (LLNL) Tiger Team Assessment}

No technical work related to this site was conducted during this reporting period.

\subsubsection{Brookhaven National Laboratory Tiger Team Assessment}

There was no activity on this task during this reporting period.

\subsubsection{Sandia National Laboratories (SNL), Livermore Tiger Team Assessment}

In February, file closeout activities were performed on the SNL, Livermore Tiger Team Assessment. No work was performed on the SNL, Livermore Tiger Team Assessment from March through August.

\subsubsection{Paducah Gaseous Diffusion Plant Tiger Team Assessment}

No technical work related to this site was conducted during this reporting period.

\subsubsection{Hanford Tiger Team Assessment}

No technical activities were performed during this reporting period. 


\subsubsection{Argonne National Laboratory Tiger Team Assessment}

Performance Objectives and Criteria (POC) for Environmental Audits were submitted to DOE July 17,1991 . Work continued on providing documentation to support the use of the POC for programmatic assessments.

\subsubsection{Oak Ridge National Laboratory Tiger Team Assessment}

The HALLIBURTON NUS Group Coordinator reviewed the draft Final Tiger Team Assessment Report to ensure revisions to the draft report were properly incorporated. Comments were provided to DOE on February 19. Other tasks included discussions with DOE on Draft Action Plan open items, review of Tiger Team Assessment follow-up material, and task closeout.

\subsubsection{Lawrence Berkeley Laboratory Tiger Team Assessment}

The closeout for the LBL Tiger Team Assessment was held on February 15, 1991. Horizontal review comments were incorporated into the draft report during March and the report was finalized during May.

\subsubsection{Princeton Plasma Physics Laboratory Tiger Team Assessment}

During this reporting period, most of the PPPL Tiger Team efforts took place. Onsite activities, including document review and report preparation, were completed on March 12, 1991; and post-assessment tasks included internal HALLIBURTON NUS peer review, incorporation of peer review and other comments. Team members also reviewed and commented on Tiger Team-related documentation. File closeout activities were also initiated during this period.

\section{$2.11 \quad$ Environmental Audits}

\subsubsection{Bonneville Power Administration Environmental Audit}

Audit-related documents were reviewed by team members and comments were provided to DOE on April 22, 1991; and file closeout activities were completed. This task is complete. 


\subsubsection{Maywood Interim Storage Site Environmental Audit}

No technical activities were performed during this reporting period.

\subsubsection{Western Area Power Administration Environmental Audit}

Formal comments of the Audit Team specialists on the WAPA Draft Action Plan were submitted to DOE OEV on March 7, 1991.

\subsubsection{North Las Vegas Facility Environmental Audit}

The camera-ready copy of the final audit report was submitted to DOE on March 15, 1991. The team submitted comments to the Draft Action Plan on April 11, 1991 and the Final Action Plan on June 3, 1991.

\section{$2.12 \quad$ Continuity of Services}

\subsubsection{Sandia National Laboratories - Albuquerque}

As part of the continuity of services arrangement, one person attended the preassessment meeting, and two individuals provided advice and support to the DOE team management during the on-site assessment 4/15/91 - 5/24/91. A course on radiological concepts was presented to DOE/OEV on June 11 and 12, 1991.

\subsubsection{Idaho National Engineering Laboratory}

A HALLIBURTON NUS Group Coordinator provided technical assistance, guidance, and support to the INEL Tiger Team Environment Subteam Leader, Assistant Subteam Leaders, and contractor team members throughout the INEL Tiger Team. Activities involved the pre-assessment visit, assessment planning meetings and phone consultations, and on-site support. 


\subsubsection{Morgantown Energy Technology Center}

HALLIBURTON NUS provided two technical specialists to serve as transition support for DOE during the Tiger Team Assessment at the Morgantown Energy Technology Center (METC). One specialist was assigned to the Environment Subteam as a Special Assistant to the Subteam Leader. His responsibilities were to use his background and experience in DOE environmental issues to assist the Subteam Leader in focusing on the substantive environmental problems at METC. The other technical specialist was assigned to provide transition support for the Management Subteam of the METC Tiger Team as a Special Assistant to the Management Subteam Leader. His responsibilities were to act as an interface between the Environment and Management Subteams and to provide support to the Management Subteam Leader for environment, safety and health (ES\&H) issues.

\subsubsection{Solar Energy Research Institute}

All activities for this task took place during this reporting period. Pre-assessment activities began in June and consisted of document review and the pre-site assessment planning meetings at ADL (Cambridge, MA) on June 24-25, and at DOEGTN, on June 28, 1991. On-site activities took place between July 15 and August 3, 1991 and included technical advice and support to the SERI Tiger Team Environment Subteam Leader, Assistant Subteam Leader, and contractor team members. This task is complete.

\subsubsection{West Valley Demonstration Project}

Activities during this reporting period included pre-audit preparation from July 8 , 1991 to July 26, 1991. Advice and support were provided to the DOE Team Leaders and the ADL Team during the environmental audit of WVDP, July 29, 1991 to August $16,1991$.

\subsection{Program Management}

- HALLIBURTON NUS Project Management continued to monitor and review ongoing Survey, Prioritization, Audit and Tiger Team activities. 
- HALLIBURTON NUS continued to prepare and review overall budgets and expenditures for the entire contract to ensure project completion within budget.

- On several occasions, HALLIBURTON NUS met with DOE to discuss the budget and anticipated expenditures to complete tasks for this contract.

- HALLIBURTON NUS Project Management prepared and submitted Task Plans for each of the Task Assignments issued by DOE during this reporting period. Project Work Plans were prepared or revised when necessary and distributed internally to all Survey, Prioritization, Tiger Team and Audit participants.

- Monthly progress reports have been submitted to DOE to track technical accomplishments and budget expenditures, in accordance with the contract requirements.

- Mr. Mark Francis of HALLIBURTON NUS was interviewed by the DOE Inspector General on September 16, 1991 regarding Inventory Difference Special Issue activities conducted during the Portsmouth Tiger Team investigation. 